\title{
O Direito Internacional na última conflagração
}

\section{José Dalmo Fairbanks Belfort de Mattos}

Terminou a Segunda Conflagração Mundial. Nunca se verificara conflito de proporções tão gigantescas, não só em relação ás forças em choque, como tambem em face do âmbito atingido pela guerra.

Até aqui, a "linha de frente" era relativamente tênue. A área de operações estendia-se apenas até o alcance máximo das peças.

o Estado beligerante entrava somente em contacto direto com os combatentes, ou com as populações das áreas invadidas. Os civis, moradores em zonas ainda não ocupadas, escapavam ao influxo direto da guerra. E seriam atingidos, quando muito, por meio de "raids" esporádicos...

Agora, tudo mudou. 0 território nacional inteiro é, permanentemente, uma potencial área de combate. A "linha de frente" estende-se em profundidade, e "passa pelas usinas de material bélico", ou "pelos centros onde se ativa a produção".

Fala-se em "nova concepção de neutralidade", em não beligerancia, em pré-beligerancia. Estuda-se, pela primeira vez, a repressão sistémática dos "crimes de guerra". E, como tais se consideram, não apenas os delitos praticados "in bello", mas tambem a preparação, o incentivo á guerra de agressão.

É, pois, chegado o momento de pesquizar o que realmente se passou nestes seis longos anos de luta. E verificar se as normas anteriormente admitidas no direito inter- 
nacional geral puderam realmente resistir á contra-prova dos fatos.

\section{I. $^{\circ}$}

Os meios para solução amigavel dos conflitos internacionais

Todos os meios, penosamente elaborados, em sucessivas conferencias e Tratados, quer para impedir a guerra, quer para limitar-lhe a estensão, não lograram alcançar o objetivo colimado.

As sanções econômicas não surtiram efeito, no caso da Etiópia. A mediação anglo-francesa redundou $\mathrm{n}_{0}$ Acôrdo de Munich. E apenas retardou a deflagração do litỉgio. A “politica de não reconhecimento" não poude conter o avanço japonês pelo Extremo-Oriente.

Os Paizes do Eixo e seus Estados vassalos regeitaram quasi sempre ofertas de arbitragens. $E$ não invocaram, sequér, o art. 19 do Pacto da S. D. N., o qual admitia a revisão política dos Tratados, que não mais se adatassem á realidade internacional.

O Tribunal de Haya e o C. P. J. I. não foram chamados a solucionar pendencias entre o Terceiro Reich e a TchecoSlovaquia ou a Yugo-Slavia, embora as Altas Partes em conflito fossem signatárias de pactos diversos, em que se reconhecia a competencia jurisdicional destas duas Côrtes.

Tais fatos revelam, pois, que os assim chamados "meios de solução pacífica dos conflitos" só operam realmente:

a) ou quando os Estados em choque, de fato, desejam evitar a guerra;

b) ou quando esse "desejo" lhes é imposto por uma força exterior. 
II. ${ }^{\circ}$

Início da guerra

Duas concepções encontravam-se em debate.

Desejavam alguns que as guerras fossem declaradas de maneira solene. E que medeiasse um lapso de tempo consideravel entre a declaração e o inicio efetivo das operações.

Pensavam outros (militares, sobretudo) na conveniencia de um ataque massiço - sem prévia declaração de guerra, destruindo, de surpreza, os centros vitais do inimigo, e tornando a zona adjacente á fronteira uma "no man's land", aberta ao avanço do adversário, (Carta do general italiano Dounet ao escritor Jean Romeyer, inserta em seu "Étude sur l'aviation italienne", pag. 12).

O primeiro metodo, afirmava Alberic Rollin, teria a vantagem de permitir aos beligerantes reconsiderar sua alitude, antes que a honra nacional estivesse irremediavelmente comprometida com o princípio das atividades bélicas.

O segundo (rotulado por DouHET, como atingindo um fim defensivo por meio de uṃa ação ofensiva) visava obter a destruição dos elementos essenciais á defeza do inimigo, antes que ele suspeitasse, sequer, de que se encontrava em guerra.

A Terceira Convenção, assinada na $2 .^{a}$ Conferencia da Paz, exigia

“advertencia prévia e não equívoca que terá, "seja a forma de uma declaração de guerra moti"vada, seja a de um ultimatum, com declaração "de guerra condicional" (art. 1. ${ }^{\circ}$ )

o Projecto de Gand completava-o estipulando que “as hostilidades só poderão começar, depois de "um prazo suficiente para que a regra do aviso 


\section{"prévio e inequívoco não possa ser elidida" (art. 3. ${ }^{\circ}$.}

Epitacio Pessôa fixava-o em 24 horas (Projeto de Codigo de Direito Internacional, art. 387).

Ora, as obrigações assumidas em Haya foram religiosamente respeitadas pela Inglaterra e França, em relação á Alemanha. A Segunda Conflagração Européia estendeu-se ao Ocidente, após a entrega em Berlim de dois ultimatuns paralelos, dando o prazo de vinte e quatro horas para que cessasse a invasão alemã na Polonia. Se tal não acontecesse, França e Inglaterra declarar-lhe-iam a guerra.

$\mathrm{E}$, realmente, só após a expiração do prazo concedido, foi votada, em Londres e Paris, a existencia do estado de guerra. E somente então se iniciaram as operações correspondentes.

Os Estados Unidos foram ainda mais longe, no respeito a este principio. Mal grado existisse de fato, a beligerancia com o Japão, desde o ataque a Pearl Harbour, - o Congresso Americano proclamou a existencia da guerra, no dia imediato.

Proclamou, e não apenas neconheceu-lhe a existencia, o que seria mais curial.

A Itália, fiel ás tradições dos últimos cem anos, declarou solenemente a guerra aos aliados. Não estabeleceu, porém, qualquer prazo para que a notificação chegasse aos respetivos governos. E iniciou, de maneira imediata. as atividades militares.

O Reich e o Japão, pelo contrário, preferiram a guerra não declarada, que muito facilitava a blitzkrieg.

\section{III.}

Efeitos jurídicos da guerra

Ainda aqui, os juristas se dividiam. Pelo menos, em \{eoria. 
A doutrina francesa desejava restringir as consequencias jurídicas da beligerancia ás tropas em choque. Distinguia entre o nocens e o inocens. E só áquele estendia o jus nocendi, caraterístico da guerra.

O Estado beligerante teria obrigação de assegurar aos inimigos, nele domiciliados, o uso e gôzo dos direitos privados. Pois, nesta concepção, quando o Estado recebe um estrangeiro em seu território, firma um contrato tácito, comprometendo-se a proteger-lhe os interesses.

A concepção inglesa (insular, ou anglo-germanica) era nui diversta. Consideravam-se inimigos todas as pessôas nascidas em pais inimigo, ou nele residentes quando o domicílio fosse adquirido formalmente, mediante requerimento individual.

Tais pessôas perderiam até o direito de estar em juizo. LoRIMER chama-as de ex-lex. Admite que os contratos, com ele firmados, são nulos e ilegais. A aquisição de seus bens podia constituir, para o nacional, um crime de misdemeanour (infração ás leis de carater público, segundo Blacks TONE).

Era lícito expulsá-los do Pais, ou sugeitá-los a domicílio forçado, enquanto durasse a conflagração.

A propriedade tornava-se hostil, em função do domicilio de seu proprietário. Era lícito destruí-la ou confiscá-la. As compnhias tinham sua situação regulada pela lei do domicilio (séde), ainda quando os componentes tivessem domicílios em Estados neutros.

Na prática, porém, a Inglaterra vinha, no último século, mitigando consideravelmente o rigôr dos princípios aludidos.

As associações religiosas, culturais e beneficentes poderiam ser declaradas "não inimigas" pelo Rei. Certo comércio de mercadorias, que não contribuissem para o esfôço de guerra, poderia ser autorizado, por meio de "Orders in Council". 
Admitia-se, mais, a validade juridica dos contratos, firInados por prisioneiros britânicos com súditos inimigos, quando tais transações redundassem em vantagem efetiva, ou minorassem-lhes os sofrimentos.

A concepção francesa, por outro lado, sofria consideraveis restrições. Já em 1914, medidas várias cercearam a capacidade 'contratual dos súditos adversários. E, ;mais tarde, criaram-se até campos de concentração.

Nesta conflagração, o temôr á "quinta-coluna", a importancia do fator econômico na direção da guerra, o receio da espionagem, fizeram adotar, quasi integralmente, o velho ponto de vista anglo-germânico.

Os navios mercantes inimigos foram embargados, ao primeiro sinal de hostilidades, mesmo quando surtos nos portos nacionais. Bloquearam-se os bens dos súditos adversos. Removeram-nos dos pontos chegados ao litoral, ou da proximidade das industrias-chave. Concentraram-se os suspeitos em campos de concentração.

Não se lhes negou, porém, por inteiro, o jus standi in judicio. Assim, de acôrdo com a lei inglesa, os alemães e seus aliados puderam litigar, perante as "Côrtes de Prezas". $\mathrm{E}$, embora desprovidos, em t'ese, de capacidade processual, era-lhes a mesma reconhecida, pro hac vice, quando se tratava de impugnar a legalidade da captura, ou o carater hostil da mercadoria aprezada (Vide Josef Kunz - British Prize Cases", 1940, 1941, in "The American Journal of International Law, vol. 36/204).

Assegurou-se-lhes até o direito de defeza, pela nomeação de defensores ex-officio, caso não conseguissem advogados voluntários.

Quanto á propriedade inimiga, as lei foram geralmente muito enérgicas. Uma "Order in Council", irradiada 
a 4 de Setembro de 1939, ordenava aos ingleses, residentes no Reich, que destruissem seus haveres - caso os mesmos pudessem contribuir para a vitória germânica.

$\mathrm{E}$, em Outubro do mesmo ano, as autoridade militares do Terceiro Reich sentenciavam á morte um cidadão britânico, que incendiara suas quatro fazendas de trigo, em obediencia ás ordens recebidas.

O comércio foi totalmente proibido, em relação aos territórios inimigos. E mais tarde, ás áreas ocupadas por este.

Assim, em Julho de 1940, uma "Order in Council" proibia, aos cidadãos do Reino Unido, mercadejarem com a província de Finmark, e o porto de Narvik, recentemente evacuados pelas forças aliadas.

Até a própria França sentiu o influxo de tal corrente. O "Journal Officiel" de 4/9/1939 (dia seguinte á declaração de guerra) estampa dois decretos-lei. Um "relativo ás interdições e restrições de negócios com inimigos, e as pessôas que se encontrem em território inimigo, ou ocupado por este".

Outro, "concernant la declaration et mise sous sequestre des biens appartenant à des ennemis".

A nossa legislação interna sofreu, tambem, a influencia desta orientação geral.

Dahi surgirem decretos-leis nitidamente influenciados pela concepção anglo-germânica da guerra.

$\mathrm{O}$ decr. n. ${ }^{\circ} 4.638$

"faculta a recisão de contrato de trabalho com "os súditos das nações com as quais o Brasil rom"peu relações diplomáticas, ou se encontra em "estado de guerra". 
$O$ decr. n. 4.717 exige

"ás firmas individuais e sociedades comerciais... "constituidas por súditos alemães, italianos ou "japoneses",

que façam as declarações a que alude o art. $10^{\circ}$

$\mathrm{O}$ decreto-lei $\mathrm{n} .^{\circ} 4.636$ cassa a autorisação de funcionamento ás companhias de seguro alemãs e italianas.

Outros decretos-leis e portarias instituem a exigencia dos salvo-condutos. Tornam obrigatório que os súditos estrangeiros, considerado inimigos, solicitem prévia autorização policial para mudança de domicílio, etc.

Antes mesmo do inicio real das hostilidades, já o Decreto-lei $\mathrm{n}$. 4.166 , de $11 / 3 / 42$ bloqueava os bens dos suditos alemães, italianos e japoneses. Consequencia da rutura de relações diplomaticas com tais Estados.

\section{Os tratados internacionais}

A Europa caracterizava-se, de 1919 a 1935, pela pletora de tratados, estabelecendo alianças, "ententes" e blócos regionais. Tais e tantos se tornaram (assinala Guido GoMel= LA, em seu recente trabalho "Principios básicos para uma ordem internacional), que a própria multiplicidade os tornava inoperantes.

Obrigações que se contradiziam. Compromissos que se anulavam, destruindo-se.

Estados havia, vinculados por Pactos de não-agressão $\mathrm{e}$ perpetua amizade com seus vizinhos. Mas que seriam chamados a lutar contra estes, se terceiras Potencias fossem agredidas.

Assim, a Turquia firmava com a Italia, um "tratado de neutralidade, conciliação e solução judiciária" (30/5/1928). Deveria, porém, ex-vi do Pacto da Entente Balkânica, cor- 
rer em auxílio da Yugo-Slavia ou da Grécia, caso tais Paises fossem invadidos pelas forças italianas.

A mesma Entente Balkânica obrigava os exercitos turcos a socorrer a Yugo-Slávia em caso de guerra com a IHungria. A tanto obstava-lhe, porém, o "tratado de nelltralidade, conciliação e arbitragem húngaro-turco", firmado aos 5 de Janeiro de 1929.

Alguns Tratados declaravam-se meramente defensivos, mas não conceituavam os casos de agressão-indirecta. Daí a inoperancia quasi geral de tais Acordos.

$O$ vasto plano francês da segurança, por meio de Acôrdos Regionais, esboroou-se.

O Pacto de Locarno estabelecia uma rêde de "Puissances garantes", contra o violador do statu-quo europeu.

"Pour les frontières occidentales l'Allemagne, "l'Angleterre, la Belgique, la France, l'Italie, "et, si la France est attaquée, la Pologne et la "Tchéco-Slovaquie; pour les frontières orienta"les, la France" (Mariotte, ap. Lobo d'Avila "Lima - "Da Sociedade das Nações", pag. 155, “nota)

Além disto, a Bélgica e a França conservavam-se unidas, em face de um ataque alemão. A "Petite Entente" grupava a Tcheco-Slováquia, a Yugo-Slávia e a Rumânia contra as pretensões revisionistas da Hungria e da Alemanha. E a "Entente Balkânica", formada pela Grécia, Turquia, Yugo-Slávia e Rumânia visava conter a Bulgária, sempre a sonhar com o dominio da Macedônia.

Ora, a Itália, - Potência signatária do statu-quo locarniano, exigiu Nice e a Saboia, e ao fim invadiu as fronteiras da França. As mesmas fronteiras que se comprometera a assegurar.

A Petite Entente não funcionou, no caso dos Sudetos. Nem a Entente Balkânica, por ocasião da guerra italo-grega. Ou da invasão búlgara, em territorio helênico. 
Daí a inoperancia quasi geral de tais Acôrdos.

Os tratados bi-laterais funcionaram, de maneira geral, com maior eficiência. Destacamos, entre eles, a aliança anglo-franco-polaca, o Tratado anglo-grego, cujo cumprimento forçou a Inglaterra a desguarnecer a Cirenáica, e possibilitou a contra-ofensiva de Von Rommel, em 1941.

Os Pactos de não-agressão, formados pela Alemanha com a Polônia, a Tcheco-Slováquia e a Rússia, somente foram observados enquanto conveiu a Berlim. Da mesma forma, o Tratado fino-soviético de 21/11/1932 foi violado pela Rússia, no inverno de 1940.

Enquanto isso, o acôrdo de não-agressão russo-japonês vigorou até o decurso total do prazo, para o qual fôra assinado (1).

\section{A cláusula "rebus sic stantibus"}

Verificou-se, porém, um caso interessante. Trata-se da tentativa soviética para justificar a incorporação, a seu território, da Polônia Oriental.

Os governos de Moscou e Varsóvia estavam ligados por dois acôrdos internacionais: - o tratado de Riga (1921) estabelecia as fronteiras entre os dois Estados. E o Pacto de não-agressão, assinado em 1934, constituia um compromisso formal de respeitá-las.

Entretanto, a 17 de Setembro de 1939, as forças soviéticas franqueavam a linha divisória, desde Vilna á frontei.ra rumena. Aprisionavam em Tarnopol a brigada tcheque, que se aprestava a lutar contra os nazistas. Estabeleciam a jurisdição soviética, nos distritos ocupados.

(1) Os promotores aliados, no Tribunal de Nuremberg, acusam agora a Alemanha de ter violado 74 tratados de varia espécie, sendo 15 Pactos Gerais e 59 acôrdos bilaterais (sessão de 4-12-45). 
O Kremlin publicava uma nota, declarando não mais se considerar jungido pelos passados acôrdos, eis que, em virtude das vitórias alemãs, já não existia o Estado Polonês, com o qual os firmara.

Assim, a ocupação explicava-se, visando "restabelecer a ordem e a paz, que não mais estão garantidas neste momento, devido á desorganização do Estado Polonês e a fuga de seu governo".

Políticos russos sintetizaram a nota, na seguinte frase: - "O Estado Polonês deixou de existir, e as minorias russas precisam ser protegidas". (Vide texto inserto na "Folha da Manhã", 17/9/1939, ed. extraordinária).

$\mathrm{E}^{\prime}$ bem de ver que esta invocação indireta da cláusula "rebus sic stantibus", qual condição resolutiva, incluida tacitamente em acôrdo bilaterais, envolve uma interpretação por demais estensiva.

Nem mesmo Korovine, - o professor de Direito Internacional Público, na Universidade de Leningrado, dá-lhe tal amplitude.

Cumpre notar que, aos 17 de Setembro, consideraveis forças polacas resistiam, ainda, aos ataques germânicos. Dois exércitos regulares lutavam, ás margens do San. Varsóvia não se rendera. 0 governo polonês funcionava, em território nacional. E apenas retirar-se-ia no dia imediato para a Rumânia, uma vez que o ataque de Moscou, á retaguarda das tropas, que se empenhavam na luta antinazista, tornava impossivel qualquer resistencia.

Só então, também, a 18 de Setembro, 300 aviões polacos aterrisaram em Cernauti, buscando refúgio em território da Bukovina.

Ora, se a 17, a soberania polaca ainda se fazia sentir sobre dois quintos do território; se o governo contava com o apôio de forças regulares, embora inferiores ás do invasor; se sua autoridade era ainda respeitada na área não atingida pelos germânicos, - como admitir houvessem caducado os acôrdos de Riga ou Varsóvia? 
Ainda mais : - restaurada, em 1943, a soberania da Polonia, readquirida in totum a jurisdição aliada sobre os territórios, como justificar-se a exigencia russa de que tal soberania não mais se exercesse sobre a Ukrânia Oriental, e zonas situadas a leste da Linha Curzon?

Na mesma ocasião, a Rumania encontrava-se ligada á Polônia por uma aliança defensiva, cujas cláusulas previam uma resistencia comum, em caso de invasão russa. Desligou-se, tambem, do tratado. Declarou-se neutra, aos 18 de Setembro. Desarmou os elementos, que haviam procurado refúgio em seu território. Internou as forças e os membros do governo de Varsóvia. Permitiu-lhes, porém, mais tarde, abandonar o Pais. E constituir, no Estrangeiro, o primeiro núcleo do exército polonês livre, que havia de lutar, na Itália, ao lado das divisões britânicas.

Em ambos os casos, porém, não tentou explicar suas atitudes, injustificaveis ambas em face do direito internacional.

\section{Outras questões diplomáticas}

\section{A co-beligerancia}

O Direito Internacional conhecia, até 1942, apenas dois tipos de associação de Estados, para fins militares: a aliança e a "entente". Esta mais imprecisa, mais elástica do que aquela.

O conflito atual criou a co=beligerancia. Podemos definí-la como "situação de fato, em que duas ou mais Potencias unam seus esforços militares, tendo em vista um fim determinado, sem contudo estabelecer igualdade de direitos entre as mesmas, nem alterar as situações de jure pre-estabelecidas". 
A co-beligerancia foi creada pelos Aliados, para definir a situação internacional das forças italianas, em operações nos Abbruzzos, após o armistício.

Combatiam ao lado dos exércitos anglo-americanos. Dispunham de comandos próprios. Aplicavam suas próprias leis militares. Mas tal associação, exclusivamente limitada ao esforço de guerra, não cancelava, ipso-jure, as condições do Armistício. Nem facultava, ao governo de Badoglio, tratar as Potencias Ocupantes em pé de igualdade. Cfr. - nossa entrevista á "Folha da Noite", em 1943).

E' obvio, porém, que a lógica natural dos acontecimentos aproxime, cada vez mais, o co-beligerante da posição de aliado, para a qual tende, como status-limite.

\section{A política do não-reconhecimento}

O princípio do não-reconhecimento surgiụ com a nota americana, enviada á China e ao Japão, relativamente ao "incidente mandchủ".

Stimson nega-se a reconhecer ato ou tratado contrário ao Pacto Kellog, - principalmente os que derivam de força, empregada como instrumento de política nacional.

Aprovada pela S. D. N., em 11/3/1932. Reafirmada nas Conferencias Pan-Americanas de Montevidéo, Lima e Havana, inserta na. "Carta do Atlantico", essa norma de conduta predominou por parte das Potencias Aliadas e Neutras, durante a atual conflagração.

Não foram reconhecidos, internacionalmente, os governos de Quisling e Mussert. Não o foi a separação da Croácia, nem a anexação da Slovênia ao Império Italiano.

A Paz de Vipuri, imposta pela U. R. S. S. á Finlândia, não obteve o "placet" dos governos estranhos ao Eixo, que tambem não reconheceram a incorporação dos Estados Balticos á Rússia Soviética. 


\section{Os governos extra-territoriais}

Corolário lógico de tal situação, os governos extra-territoriais da Polônia, Noruega, Bélgica, Holanda, Yugo-Slávia, e Grécia, sediados em Londres, continuaram a ser considerados os governos legítimos. E a exercer, no exílio, todos os atos decorrentes da soberania.

Reis e primeiros ministros gozavam de imunidades concedidas aos Chefes de Estado. Exercam o direito de legação, assinavam tratados, prosseguiam na atividade legislativa, sendo suas Leis e Decretos publicados na Imprensa Oficial Britânica.

Suas forças armadas aplicavam as normas do Direito Penal Militar respetivo, e apenas sofriam as resírições necessárias á coordenação geral do Esfôrço Aliado.

\section{0 status de refugiado}

O Conflito de 1939/45 apresentou uma peculiaridade que o aproxima juridicamente das "guerras civis internacionais", oriundas da Reforma, ou decorrentes da Revolução Francesa.

Foram sem numero os refugiados políticos, que buscaram o amparo das Democracias. Fugiram de seu Pais, antes de deflagrar a contenda, e vieram buscar, do outro lado da fronteira, um "clima" consentâneo ás idéias que professavam.

Daí surgir um verdadeiro "status de refugiados". "Status" diverso do de simples asilado. E que se não confunde com a apatrídia.

Podestá Costa nega sua poss'bilidade, em artigo inserto na "Jurisprudencia Argentina" (1936) .

Mas os Tribunais Aliados reconheceram, vezes sem conta, tal circunstância como excludente do carater hostil. E com força para preterir o simples critério da nacionalidade. 
Assim, aos 16/11/39, o Tribunal Civil do Sena mandou tornar sem efeito o embargo que onerava os bens da Sociedade "Le Zenith",(embora pertencente a alemães), visto dois dos sócios estarem em França, na qualidade de refugiados.

Meses mais tarde, no "Caso Spielmann", o mesmo Tribunal isentava os RR. das restrições comerciais decorrentes da guerra. Cancelava o embargo. Reconhecendo tratar-se de cidadãos austríacos, que, desde a "Anschluss" viyiam nos Estados Unidos (Cfr. - Martin Domke - "Pro= blems of international law in french jurisprudence 1939/41", in "The American Journal of international law" vol. 36 pags. 24-25).

\section{PARTE}

\section{As leis de guerra}

O Prof. Dr. Braz Arruda, em interessante Curso, publicado na "Revista da Faculdade de Direito", em 1927, considerava como parte integrantes do direito escrito da guerra:

$1,{ }^{\text {a }}$ a $3 .^{\mathrm{a}}$ - Convenções de Genebra, Paris e S. Petesburgo;

$4 .^{a}$ - Convenção de Haya, de 1899;

$5 .^{a}$ - Declaração sobre balas dum-dum;

6. ${ }^{\mathrm{a}}$ - Declaração sobre explosivos lançados de balões;

$7 .^{\mathrm{a}}$ - Declaração sobre os gazes asfixiantes;

$8 .^{\mathrm{a}}$ - Idem, para aplicar á guerra maritima, os princípios da Convenção de Genebra sobre os feridos;

$9 .^{a}$ - Convenção de Haya, sobre a abertura de hostilidades;

$10 .^{a}$ - Idem, sobre negociantes estrangeiros, uma vez começada a guerra;

11. ${ }^{\text {a }}$ - Idem, sobre a transformação de navios mercantes em belonaves;

$12 .^{\mathrm{a}}$ - Idem, sobre minas submarinas; 
$13 .^{\text {a }}$ - Idem, sobre o bombardeio naval;

$14 .^{\mathrm{a}}$ - Idem, sobre a captura.

$15 .^{a}$ - Convenção de 1907, sobre direitos e obrigações dos neutros nas guerras marítima e terrestre.

Desta enumeração, deduz-se que o direito positivo, entâo vigente, tinha como pressuposto a existencia de normas peculiares á guerra terrestre e á luta nos mares. E a guerra aérea começava a debuxar-se. Aplicavam-se-lhe óra os princípios norteadores das operações em terra, óra os da guerra marítima, segundo a natureza das tarefas entregues á aeronáutica.

A Segunda Conflagração alterou os dados do problema.

A íntima conexão entre as esquadras e as forças do ar - já prevista por Axel Blatr, na "Conferencia Interparlamentária", - deu origem á guerra aéreo-naval, como um todo indissoluvel.

Exemplos típicos: - os bombardeios de Taranto, em 1940; as batalhas de Matapan, Mar do Coral e Midway; a caça ao couraçado "Bismarck", etc.

E não é só. A Inglaterra criou as "Forças para Operações Combinadas" (Comandos), com uma íntima conexão entre as tropas de terra, mar e ar. Os Estados Unidos seguiram-lhe o exemplo, instituindo os "Rangers"

ora, tais unidades de desembarque, conduzidas em harcaças, apoiadas pelos canhões navais e pelas esquadrilhas de bombardeiros - a que convenções deveriam obedecer?

E os paraqueristas e divisões aero-transportadas - já cognominadas de infantaria aérea, regular-se-iam por que convênios internacionais?

Quer-nos parecer, pois, que muitas das convenções óra vigentes deverão ser revistas, afim de melhor se entrosarem no futuro . 


\section{I. ${ }^{\circ}$ \\ A guerra terrestre}

Os acôrdos, relativos á guerra terrestre, tiveram eficácia muito variada.

A CONVENÇÃO DE GENEBRA (revista em 1929) foi geralmente respeitada, na frente ocidental e operações norteafricanas.

Conta-se até haver o General Von Rommel sido medicado por uma ambulância inglesa, durante a segunda Batalha de Tobruk.

Já no Oriente, tal não se deu. A aviação japonesa é acoimada de haver destruido, por meio de sucessivos bombardeios, as instalações hospitalares de Bataan, mau grado ostentarem, estas, visiveis emblemas da Cruz Vermelha.

Não se conhece caso de se haver empregado balas dumdum, ou apetrechos que fizessem sofrer desnecessariamente os feridos.

Os americanos acusam, no entanto, as tropas alemãs de envenenarem vitualhas, durante a retirada para além de Colônia.

Os usos e leis de guerra, regulando os direitos do ocupante, para com a população inimiga, foram em geral seguidos pelas Potencias Aliadas. O "Governo Militar" (Amgot), instituido por ocasião dos desembarque na Sicília, prestou relevantes auxílios aos habitantes. Distribuiu víveres. Respeitou, quanto possivel, os governos municipais. Atribuiu autonomia regional a "podestás", eleitos, por vezes, pelos elementos do lugar.

E, ainda hoje, as autoridades anglo-americanas, que administram a Alemanha Ocidental, são acusadas pelos russos de não "expurgarem as juntas locais com grande rapidez". Vale dizer: - de manterem, em seus postos, funcionários civís da antiga situação política. 
Os Alemães, pelo contrário, saquearam cidades. Requisitaram obras de arte. Instituiram o regimen de refens, punindo com a morte de dez cidadãos de relevo, na sociedade local, os atentados contra a segurança de cada soldado germanico.

Ainda mais. Organizaram expedições punitivas, como as de Lidice e Oradour. Impuzeram contribuições de guerra a diversas aldeias.

Estabeleceram o trabalho compulsório para grande numero de operários fabrís. Contrariaram, assim, o Manual de Oxford, e outros textos doutrinários.

O tratamento de prisioneiros foi, igualmente, variavel. As Potências Aliadas mantiveram, de maneira geral, os compromissos assumidos. Permitiram que representantes de Estados Neutros visitassem os campos de concentração. $\mathbf{P a}$ garam soldo ás tropas italianas, aprisiónadas na Campanha da Abissínia, e nas operações da Cirenáica.

Os germânicos não maltrataram, geralmente, os angloamericanos capturados, (exceção feita dos paraquedistas). Mas agiram com grande crueldade para com prisioneiros franceses e slavos (Campos de Belsen, Auschwitz, Dachau, etc.).

As acusações feitas aos japoneses, no que respeita aos prisioneiros de guerra, constituem, agora, objeto de processo, instaurado em Manilha.

Merece especial estudo a aplicação das leis de guerra ás forças irregulares.

Esta guerra assistiu á eclosão de vastos movimentos subterraneos (underground), e á constituição de corpos francos (guerrilheiros, chetniks, partizans, etc.).

Os Paises do "Eixo" não lhes davam quartel. Consideravam-os franco-atiradores, ainda quando "em número respeitavel", e sob commando de oficiais da ativa. 
Os maquis foram tambem arduamente perseguidos. Durante as operações de Vercors (Alta Saboia), até mesmo os feridos, quando capturados em embrionários hospitais de sangue, foram exterminados.

Em fins de 1942, o General de Gaule tentou dar um facies regular aos seus adeptos. Organizou-os em unidades especiais (Forças Francesas do Interior, - F. F. I.). Submeteu-as ao comando supremo do General Koenig. E comprometeu-se a obrigá-las a usar distintivos e emblemas aparentes, caso lhes fosse reconhecida a beligerancia.

O "Reich" deu resposta negativa. E a Itália reconheceu, apenas, como combatentes regulares, aos componentes da "Coluna Leclerc", - organizada na Africa Equatorial, em quadro e moldes rigorosamente militares.

Os simples maquis continuaram, até a libertação da França, a não receber - EM TESE - o amparo das convenções internacionais.

A legitimidade de tal proceder das autoridades germânicas é discutivel. (Cfr. Declaração de Bruxelas, art. 9; "Manual de Oxford", 1880, art. 2.. ; "Instruções Americanas para os Exercitos em Campanha", art. 81).

Os REGULAMENTOS DE HAYA (1899 e 1907) declaram, em seu art. $1^{\circ}$ :

"Les lois, les droits et les devoirs de la guerre “ne s'appliquent pas seulement à l'armée, MAIS "ENCORE AUX CORPS DE VOLONTAIRES "REUNISSANT LES CONDITIONS SUIVANTES:

1 - d'avoir à leur tête une personne respon"sable pour ses subordonnés;

2 - d'avoir un signe distinctif fixe et recon. "naissable a distance;

3 - de porter les armes ouvertement; et

4 - de se conformer dans leurs opérations aux "lois et côutumes de guerre." 
Parece que as forças de Koenig, Mihailovitch e Tito preenchiam, nos últimos tempos de campanha, tais requisitos essenciais.

O mesmo não se poderia dizer dos guerrilheiros noruegueses, que sempre agiram por meio de atentados esporádicos e sem organização aparente.

\section{A guerra naval}

A guerra naval suscitou, nesta Conflagração, as seguintes controvérsias: - limites geográficos da área de combate; colocação de minas magnéticas; direitos e deveres do Estado bloqueador; prerrogativas e obrigações na guerra submarina.

Poucas normas internacionais vinculavam os beligerantes: a Convenção de Londres não fôra ratificada por Potencia alguma. E a Inglaterra denunciara, anos atraz, a 6. Convenção da $2^{\mathrm{a}}$. Conferencia de $\mathrm{Paz}$, não mais constituindo, pois, norma obrigatória.

Cumpre assinalar o rigoroso cumprimento, por parte dos Aliados, dos dispositivos, aplicando a Convenção de Genebra á guerra maritima.

Os navios hospitais militares receberam o tratamento dispensado aos estabelecimentos da Cruz Vermelha. Os náufragos foram recolhidos em grande número. $\mathrm{E}$ assegurada a "inviolabilidade do pessoal religioso, médico e hospitalar dos navios capturados", conforme determinava o Acôrdo de 1907, art. 16.

$\mathrm{O}$ "corso" propriamente dito não foi utilizado pelos Aliados, embora os Estados Unidos não houvessem aderido á Convenção de Paris.

Os Paizes Aliados proibiram, logo no início da luta, qualquér comércio com o Reich. A Grã-Bretanha publicou, por seus consulados, listas pormenorizadas, enumerando mercadorias, que seriam consideradas "contrabando abso- 
luto" e outras incluidas entre as de "contrabando condicional".

Mencionou, na primeira categoria, armas, munições, explosivos, combustiveis, veículos, animais necessários ao transporte, meios de comunicação, moedas, ouro em barra, titulos de dívida-ouro, etc.

Int'egrava a segunda espécie

“toda e qualquer espécie de alimentos, comesti"veis, alimentos para animais, forragem, artigos

“de vestuário, artigos e materiais empregados "em sua produção".

(Vêr a lista completa no "Estado de São Paulo," de 9/9/39).

Meses após, aos 27 de Novembro de 1939, uma "Order in Council" decretava o BLOQUEIO ECONÓMICO DA ALEMANHA, como represália pela colocação de minas magnéticas.

Era o LONG DISTANCE BLOCKADE que renascia, coerente com os antigos ensinamentos do Dr. LuHsington:

"Para que o bloqueio seja efetivo exige-se ape"nas que a costa seja vigiada por uma força su"ficiente, para tornar a saida e entrada perigosa" “(vide OpPenheim, International Law).

Tal prática merecera, na outra Grande Guerra, violenta critica dos Estados Unidos. Dissera, então, a Chancelaria Americana, que esse modo de hostilizar não constituia bloqueio "nem na prática, nem no direito, nem no efeito".

Entretanto, havendo a Marinha Americana partilhado, mais tarde, das operações bloqueadoras (1917-18) reconhecendo-lhes dest'arte, a existencia e ser lídima captura de eventuais violadores, a oposição cessara. E, nesta guerra, nẫo se discutiu a legitimidade, EM SI, do bloqueio aliado. 
A Inglaterra reintroduziu o sistema dos "navycerts", tão bem estudado por Ritchie. Ampliou-o ao trannporte aéreo, como medida complementar de bloqueio, instituindo os "mailcerts". Editou listas negras, no que foi imitada por seus Aliados.

Todos os paises neutros admitiram a legitimidade de tais medidas.

Os incidentes no correr do Conflito reduziram-se a pormenores.

Alguns Estados impugnaram a inclusão dos gêneros alimentícios, nas listas de contrabando (memorandum argentino, de 5/1/1940). Outros tentaram restringir, geograficamente, as operações de guerra, delas excluindo o "Mar Continental" (Declaração do Panamá, casos do "Graf Spee", do "Wakama" e do "Hanover").

O Brasil protestou contra a retenção de correspondencia alemã, enviada a Paises Neutros, a bordo de navios neutros. (Caso do "Almirante Alexandrino", Abril de 1940).

A Itália, já então pre-beligerante, exigiu a liberação de navios carvoeiros, surtos em portos britânicos, e cujo carregamento destinava-se a Gênova, de onde seriam encaminhados ao "Reich" (Abril, 1940).

De todos esses incidentes, decorre, no entanto, a contrario sensu, admitirem todos que o bloqueio existia, de facto e die jure. Não se lhe impugnava a existencia, nem a juridicidade. Pleiteava-se, apenas, traçar-lhe limites, invocando a mais das vezes, convenções regionais, ás quais eram estranhos os beligerantes. (Respostas da Inglaterra, França e Alemanha, ao Conselho Inter-americano de Neutralidade).

Tais atividades navais não eram, porém, dirigidas arbitrariamente.

O direito de visita e captura excedia, é certo, os limites traçados por A. Pearce Higgins, no Curso professado perante a Academia de Direito Internacional (Recueil des Cours, vol. $\mathrm{XI} / 160)$. Dele não se isentavam nem 
"os barcos empregados na pesca costeira, nem os

"navios destinados á pequena navegação local".

Justificava-se, porém, tal proceder, dado o carater de represália que revestia o bloqueio econômico.

Admitiam-se, além disso, várias exceções. Navios, arvorando a bandeira papal, obtiveram salvo conduto para transportarem alimentos á população grega. Unidades navais da Cruz Vermelha Italiana obtiveram livre navegação pelo Mediterrâneo. E a Esquadra Britânica levou o escrúpulo até radiografia-lhes a notícia da Batalha de Matapan, dando-lhes a localização das belonaves do Eixo, afundadas ou avariadas.

O Almirantado, aliás, antes de decretar o bloqueio, respeitava a Declaração de Paris, relativa á captura. Assim, no "Caso Bennaodhui," declarou a "Côrte de Prezas" julga-la valida, por se tratar de mercadoria inimiga, transportada a bordo de navio britânico.

"If these goods had been in a neutral ship," dizem os Juizes, "the Declaration of Paris would "have applied, unless it could be shown that they "were contraband of war" (ap. JosEF Kunz, op. cit).

As medidas germânicas de contra-bloqueio já não eram tão concordes com o direito internacional.

A Convênção VIII. ${ }^{\mathrm{a}}$ assinada na $2^{\mathrm{a}}$. Conferencia da $\mathrm{Paz}$ (18/10/1907) proibira a utilização de "minas submarinas automáticas de contato". Consideravam-se ilicitas todas as minas "não amarradas", ou desprovidas de um mecanismo que as tornasse inofensivas, uma hora após seu lançamento. (art. 1. ${ }^{\circ}$ )

Declarava-se que, mesmo amarradas, tais engenhos deveriam acarretar o menor risco possivel, para a navegação pacífica (art. $3^{\circ}$ ). Exigia-se que o beligerante notificasse os 
neutros, por meio de notas diplomáticas, a existencia e delimitação dos campos minados (idem, ibidem).

Ora, as minas magnéticas não eram fixas, nem amarradas. Constituiam perigo indiscriminado, contra beligerantes ou neutros. Conservavam capacidade destrutiva por tempo indeterminado. E seu lançamento quotidiano, sem prévio aviso, de bordo de avióes especializados, modificava, dia após dia, a localização das áreas perigosas. E tornava impossivel a comunicação diplomática.

A Inglaterra somente adotou medida semelhante em fins de 1939, e a título de represália. A Argentina protestou contra ambos os adversários (memorandum citado).

\section{III.}

\section{A guerra submarina}

A guerra submarina fôra regulamentada pelo Tratado Naval de Londres, assinado em 1930. Os Estados Unidos, a França, a Grã-Bretanha e seus Dominios, a Itália e o Japão haviam decidido mantê-lo em vigôr apenas por 6 anos.

Caducou, pois, aos 31/12/1936. Dias antés, porém, as Altas Partes Contratantes firmaram um Protocolo, mantendo de pé a parte IV. ${ }^{\text {, }}$, por prazo ilimitado. Facultaram, mesmo a adesão aos demais Estados. E a Alemanha foi o primeiro a aderir, aos 23-11-36.

Quando a guerra se iniciou, o Protocolo vinculava, pois, os primitivos sinatários, e mais 34 Paises. Englobava, praticamente, todos os beligerantes.

Ora, rezava o seguinte o art. 224:

"The following are accepted as established rules of international law: -

1) - In their action, which regard to merchant ships, submarines must conform to the rules of international law to which surface vessels are subject". 
E mais :

" 2 - In particular, except in the case of persistent refusal to stop on being duly summoned, or of active resistence to visit or search, a warship, whether surface vessel or submarine may not sink or render incapable of navigation a merchant vessel, without having first praced passenger, crew and ship's papers, in a place of safety".

E não bastava intimar o navio a parar. Nem apenas permitir fossem lançados á agua os botes de salvamento. "For this purpose" continuava o Tratado" "the ship's boats are not regarded as a place of safety, unless the safety of the passengers and crew is assured, in the existing sea and weather conditions, by the proximity of land or the presence of another vessel, which is in a position to take them on board."

Esse é o texto inequivoco da lei internacional vigente.

Obrigavam-se os Estados signatários ou aderentes ao Protocolo de Londres, a assegurar aos passageiros e tripulações de navios mercantes torpedeados

“senão o mesmo confôrto, pelo menos a mes̄̄a ausência de perigos"

de que desfrutavam antes do afundamento (George GraF= ToN Wilson - "The submarine and place of safety", in "The American Journal of International Law", vol. 35/496)

Ora, confrontemos o texto supra com o que se verificou ao ser torpedeado o "Cabedelo". Fato ocorrido á noite, com mar revolto, muito ao largo da costa, sem prévio aviso, sem a intimação por meio do tiro de pólvora seca; toda a tripulação permanécia a bordo e passageiros adormecidos. 
O mesmo verificou-se em todo o decurso da guerra, desde o afundamento do "Athenia", poucas horas depois da eclosão do conflito, até os últimos dias (vide Proclamação Doenitz aos submarinos alemães, em 1943).

\section{IV. $^{\circ}$}

\section{A guerra aérea}

Discutia-se, em 1939, o problema da estensão da soberania estatal sobre o espaço aéreo.

Muitos a admitiam. Repugnava-lhes, contudo, assimilar a "atmosfera territorial" ás demais partes do território do Estado.

Nossa tese, "Direito publico Aéreo", foi criticada, por se haver referido a "território aéreo", como cons‘ituindo algo de real. Esta interpretação, no entanto, prevaleceu durante a Conflagração inteira.

$\mathrm{O}$ ar tornou-se campo habitual de operações militares. Os neutros proclamaram, por sua parte, o carater neutral de seu espaço aéreo.

Considerou-se VIOLAÇÃO DE TERRITóRIO o sobrevôo inofensivo, por aeronaves beligerantes extraviadas durante a viagem de regresso ás suas bases (protesto belga, a $13 / 9 / 39$ ), ainda mesmo quando não houvesse pousado sobre o solo.

Dinamarca apresentou em Londres, "o mais formal protesto contra o vôo sobre território dinamarquês, realizado por aviões britânicos", — sobrevôo ocasional, verificado após o bombardeio da ilha alemã de Sylt, pela R.A.F. (Março de 1940).

Baterias suiças abriram fogo contra aeronaves militares germânicas, que sobrevoavam Schauffose (22/9/39); canhões anti-aéreos suecos derrubaram um bombardeador da Luftwaffe, em 1943. 
Em todos estes casos, os governos interessados apresentaram pedidos de desculpa reconhecendo, pois, o princípio da inclusão do espaço aéreo neutro dentro da área defeza ás operações de guerra.

Dois Acôrdos apenas vigoravam quanto á guerra aérea: Um, era a velha DECLARAÇÃO assinada em S. PETSBURGO, proibindo lançar explosivos de bordo dos balões. Outro, o Pacto de Chklaver-Roerich (ratificado pelo Itamaraty, em 1935).

O primeiro, já era considerado caduco, em 1914. O segundo previa a criação de uma bandeira, com 3 aruelas de góles sobre fundo branco, visando proteger os monumentos religiosos, historicos ou artísticos, durante o bombardeio. Continha dispositivos inaplicaveis: - exigia a assinalação luminosa de tais monumentos, para resguardá-los dos "raids noturnos". Esquecia que, assim fazendo, o Estado privar-se-ia das vantagens do "blackout". E mostraria, a seus inimigos, a localização das cidades e aglomerações industriais. Não foi cumprido, nem sequer invocado.

Diversos projetos existiam. Entre eles, avultava a RESOLUÇÃO LEVAL, creando as "cidades sanitárias", - idéia votada durante o Congresso Internacional de Medicina e Farmacia Sanitárias.

CuQuoz batera-se pela adoção de "cidades-refúgio", permanentemente desmilitarizadas, onde apenas poderiam entrar crianças, velhos e mulheres, não adstritas á produção industrial.

Nenhum destes projetos, porém, fora convertido em convenções. Á sua falta, aplicaram-se ao bombarde:o aéreo as normas comumente admitidas para o canhoneio terrestre.

Admitiu-se que determinados lugares fossem considerados "cidades abertas", desde que se despojassem de qualquer defeza, inclusive D.C.A. (Paris, Manilha). Evitou-se, em alguns casos, visar objetivos de importância religiosa (Oasis de Jarabub, etc.). 
Os aeronáutas e paraquedistas aprisionados, quando em uniforme, era geralmente incluidos entre os prisioneiros de guerra. Verificaram-se algumas exceções (Massacre de pilotos da R.A.F. caidos em Trondheim), mas tal proceder foi reconhecido criminoso, e punido como tal, após a terminação da guerra.

As aeronaves sanitárias gozavam dos privilégios inerentes á Cruz Vermelha (Convenção de 1907, aplicada, por analogia, á guerra aérea).

A captura de aeronaves privadas inimigas, e de mercadorias aéro-transportadas, admitida por Holland e RENaUlT, foi permitida pelo "Prize Act" britânico:

Pois

"the law relating to prize shall apply in relation to aircraft and goods carried therein, as it applies in relation to ships ande goods carried therein".

$\mathrm{E}$ isto não apenas quando os aparelhos estivessem sobrevoando o Oceano,

"and shall so apply", continuava a lei "not wi"thstanding that the aircraft in on or over land".

Evitava-se dest'arte a solução híbrida, proposta por Fauchille. Perdurava, porém, a impossibilidade da visita prévia da aeronave. Salvo se a mesma concordasse em acompanhar o aparelho militar até ao aerodromo mais próximo. (vide Bonfils-Fauchrle - "Traité de Droit International Public, vol. II -, n. 1.440 , pag. 622).

o bloqueio aéreo, sem apoio de unidades navais, foi ensaiado com êxito sómente na repressão de revoltas hindús, na fronteira do Waristan. (Janeiro/Maio de 1939). Não foi tentado na Europa. Sua admissibilidade juridica é, aliás, negada por Lawrence e Oppenheim, sem grande fundamento. 


\section{$\mathbf{V}^{\circ}$}

\section{A guerra química}

A expressão "guerra química" é geralmente considerada sinônima da guerra de gases.

Ela fôra proibida, teoricamente, em 1899. O Tratado de Versailles considerava-a ilícita (art. 171). A Convenção de Washington $(6 / 12 / 1922)$ interditava o

"emprêgo, em tempo de guerra, dos gazes asfixiantes, tóxicos ou similares, bem assim como de todos os líquidos, matérias e processos semelhantes" (art. 50).

O Protocolo de Genebra estendia a proibição á exportação de produtos, dos quais os Estados pudessem fabricar tais meios de destruição..

Malgrado tantos textos, militares e internacionalistas previam, para esta guerra, grande emprêgo de gases vesicantes, como a mostarda, ou asfixiantes, como a iperite.

Gestrudis WoKer, na "Conferencia Interparlamentária", LoRd Ceci, na S.D.N., Guy Witta, em seu opúsculo sobre "La guerre de gaz"; o general Fries, no "Chemical Warfare", todos repizavam quadros catastróficos de desolação.

JonkheEr vaN Ex́singa, professor da Universidade de Leyde, sintetizava seus ensinamentos:

"Une chose est incontestable et incontestée:-c'est que, tandis que la Grande Guerre n'a pas encore realisé la combinaison de la guerre chimique et de la guerre aérienne, - l'aérochimie - on doit s'attendre maintenant à cette combinaison, dont seront les victimes, non pas seulement les forces armées, mais aussi les centres de population, les grandes villes, de même que des parties entières 
d'un pays" ("La guerre chimique et Iè mouvement pour sa repression", in "RECUEIL DES COURS DE L'ACADEMIE DE DROIT INTERNATIONAL”, vol. XVI).

Outros autores previam até o advento da guerra bateriológica, - já pro:bida pelo Protocolo de Genebra.

Entretanto, nada disto se verificou. O receio mútuo de represálias, impediu o emprêgo de gases asfixiantes, no Ocidente. Acusa-se os japoneses de havê-los utilizado, na frente central chineza, e no setor de Lae (Nova Guiné). Faltam. porém, comprobantes sérias.

\section{A guerra atômica}

Surgiu, porém, nos últimos dias da guerra, a "bomba atômica", empregando a energia proveniente da desintegração. E' uma nova arma fisico-química, cuja regulamentação internacional já se procura obter.

\section{VI. ${ }^{\circ}$}

Fim da guerra

A Segunda Conflagração Mundial apresentou alguns tratados de paz. (Tratado russo-finlandês de Vipuri, em 1940; acôrdo anglo-russo-iraniano, 1941).

Na maioria dos casos, porém, verificou-se um armisticio, cuja amplitude de exigencias constituia verdadeira rendição.

Equivalem, pois, á antiga deditio, com simples ressalva de uma devolução futura do pleno exercício da soberania. Estipulam-se a ocupação do território vencido, utilização de suas forças de produção, entrega do material de guerra, desarmamento integral. Cláusulas politicas restringem, temporariamente, o exercício do Poder Soberano. 
Entretanto, tal situação, bastante instavel, prevê a possibilidade de revisão. De readatação ás eventualidades de um futuro que mal se delineia.

Tentar deduzí-lo foge aos limites do presente estudo. E' o Após-Guerra que surge. Com seus problemas, bem mais econômicos que jurídicos. Bem mais políticos, que funcionais.

E a experiencia, haurida nesta Guerra, será por certo util. Porque terá demonstrado as falhas da estrutura internacional preexistente. $\mathrm{E}$ apontado diretrizes, para a construção de um mundo melhor.

NOTA: AS ARMAS " $V$ ". Os alemães usaram, na última fase da guerra, projetis-foguetes ("bombas voadoras", etc.). Tais meios de destruição, lançados de plataformas terrestres, segundo os princípios usuais de balística, deveriam regular-se pelos princípios norteadores do bombardeio terrestre.

Ora, a Declaração de Bruxelas (art. 17) exige que tais bombardeios poupem, na medida do possivel, os edifícios consagrados ás ciências e ás artes, os hospitais e pontos de reunião dos feridos e doentes. O Regulamento de Haya estende tal proteção ás instituições beneficentes (art. 27).

O bombardeio de destruição, por outro lado, tem sua legitimidade condicionada ao "carater e utilidade militar dos objetivos, que são alvejados, e não se pode declará-lo legítimo, quando, de fato, devi.do á grande distância a que deve ter lugar, é impossível ao beligerante dirigi-lo com precisão sôbre os únicos alvos que podem ser canhoneados" (Bonfils-Fauchille, op. cit., n.o 1.098).

Logo, a fortiori, ilegítimas são as armas, atirando sôbre a área de Londres situada a $250 \mathrm{kms}$. de distância. - Armas desprovidas de mira, sem direcão precisa e alvo determinado, - seu emprêgo constitúe grave infração ao direito internacional. 